\title{
Biochemistry in the idea of graduation students
}

Escoto, D.F. ${ }^{1,2}$, Rocha, R.A. ${ }^{2}$, Ramborger, B.P. ${ }^{1,2}$, Etcheverria, K.W.M. ${ }^{2}$, Cavalheiro, K.M. ${ }^{2}$, Roehrs, R. ${ }^{1,2}$, Denardin, E.L.G. ${ }^{1,2}$

${ }^{1}$ Laboratório de Estudos Físico-Químicos e Produtos Naturais -LEFQPN, Universidade Federal do Pampa, Campus Uruguaiana, Brasil

${ }^{2}$ Grupo Interdisciplinar de Pesquisa em Práticas de Ensino - GIPPE, Universidade Federal do Pampa, Campus Uruguaiana, Brasil

INTRODUCTION AND OBJECTIVE: Biochemistry is an interdisciplinary area that allows us to study chemical phenomena in live organisms. That way, its study is of extreme importance, in all levels, to enlarge the comprehension of natural phenomena. However, it is barely explored in the basic education and often fragmented in the higher education, or in graduation degrees that contemplate this area. Especially in the teacher training, where the fragmentation of knowledge can contribute to form wrong concepts. Based on that, this work aims to identify the concept of Biochemistry according to the future teachers of Natural Science. MATERIALS AND METHODS: The work was developed with $3^{\circ}, 5^{\circ}$ and $9^{\circ}$ semesters students of the natural science degree on Universidade Federal do Pampa. 50 students, from 18 to 56 years old, were interviewed. The data was obtained through a semi-structured questionnaire. The methodology of categorization and analysis of content with emergent categories of speech was chosen for the analysis. RESULTS AND CONCLUSION: Initially, 11 categories were chosen by content similarity. In descending order: chemical reactions in organisms, chemistry area, chemistry of life, cell metabolism, the study of living beings, origin of life, biology area, organic balance, chemical-biological study. The reports made possible to identify that most students do understand with clarity the goal of studying biochemistry. Although, we can see that there are some students that fragment the area, what means, they try to discriminate chemistry from biology. This way, they demonstrate a difficulty to comprehend biochemistry as interdisciplinary, what makes it hard to contextualize the built knowledge. It is important to develop strategies to overcome the fragmentation of knowledge, so that biochemistry can be comprehended in its fullness and help on the teaching processes that will be developed by the future teachers.

Keywords: Conception Biochemistry, Teacher Training, Science Education Acknowledgements: UNIPAMPA 